\title{
Spatial and Temporal Variability of Polycyclic Aromatic Hydrocarbons in Sediments from Yellow River-Dominated Margin
}

\author{
Su Ding, ${ }^{1}$ Yunping Xu, ${ }^{1,2}$ Yinghui Wang, ${ }^{1}$ Xinyu Zhang, ${ }^{1}$ Liang Zhao, \\ Jiaping Ruan, ${ }^{1}$ and Weichao $\mathrm{Wu}^{1}$ \\ ${ }^{1}$ MOE Key Laboratory for Earth Surface Processes, College of Urban and Environmental Sciences, Peking University, \\ Beijing 100871, China \\ ${ }^{2}$ Qingdao Collaborative Innovation Center of Marine Science and Technology, Qingdao 266100, China
}

Correspondence should be addressed to Yunping Xu; yunpingxu@pku.edu.cn

Received 28 February 2014; Revised 1 July 2014; Accepted 5 August 2014; Published 19 October 2014

Academic Editor: Zulin Zhang

Copyright (c) 2014 Su Ding et al. This is an open access article distributed under the Creative Commons Attribution License, which permits unrestricted use, distribution, and reproduction in any medium, provided the original work is properly cited.

Polycyclic aromatic hydrocarbons (PAHs) were analyzed for surface sediments and a sediment core from the Yellow Riverdominated margin. The concentration of 16 USEPA priority PAHs in surface sediments ranged from 5.6 to $175.4 \mathrm{ng} \mathrm{g}^{-1} \mathrm{dry} \mathrm{weight}^{-1}$ sediment (dws) with a mean of $49.1 \mathrm{ng} \mathrm{g}^{-1}$ dws. From 1930 to 2011, the distribution of PAHs (37.2 to $210.6 \mathrm{ng} \mathrm{g}^{-1} \mathrm{dws}$ ) was consistent with the socioeconomic development of China. The PAHs' concentration peaked in 1964 and 1986, corresponding to the rapid economic growth in China (1958-1965) and the initiation of the "Reform and Open" policy in 1978, respectively. The applications of molecular diagnostic ratios and principal component analysis suggest that PAHs are predominantly produced by the coal and biomass combustion, whereas the contribution of petroleum combustions slightly increased after the 1970s, synchronous with an increasing usage of oil and gas in China.

\section{Introduction}

Polycyclic aromatic hydrocarbons (PAHs) with two to six rings are a class of organic contaminants mainly derived from incomplete combustion of organic matter, such as coal, fossil fuel, and wood, as well as from forest fires, volcanic activities, and petroleum seeps $[1,2]$. PAHs can undergo long-range transport due to the relative recalcitrant and semivolatile properties [3]. Since many PAHs are toxic, carcinogenic, and mutagenic, they have received considerable attention from scientists, governments, and the public $[4,5]$. For example, sixteen PAH compounds have been listed as priority pollutants by the United State Environmental Protection Agency (US EPA) as well as the European Union.

Over the past several decades, the fossil fuel use in China has dramatically increased with the rapid economic development [6], resulting in significant increases in $\mathrm{PAH}$ loadings to the environment. Such situation is particularly serious in the Bohai Sea surrounding area, one of the biggest economic rims in China [7]. In 2006 alone, $4.8 \times 10^{9}$ tons of wastewater were discharged into the Bohai Sea, causing the failure to meet water quality standards for an area of 2.0 $\times 10^{4} \mathrm{~km}^{2}$ [8]. A number of anthropogenic impact studies focused on PAHs in water, suspended particulate matter and surface sediments in Bohai Sea [7, 9-13]. However, to the best of our knowledge, the spatial variability of PAHs along the transect of the Yellow River to Bohai Sea has not been reported, although the Yellow River is one of the most important conduits in transporting sediments and pollutants from land to sea in northern China $[14,15]$.

Due to the large sediment load of the Yellow River, the Bohai Sea has an exceptionally high sedimentation rate, and its sediment is an excellent recorder of historical PAHs flux. Several studies reported increasing PAH concentrations 


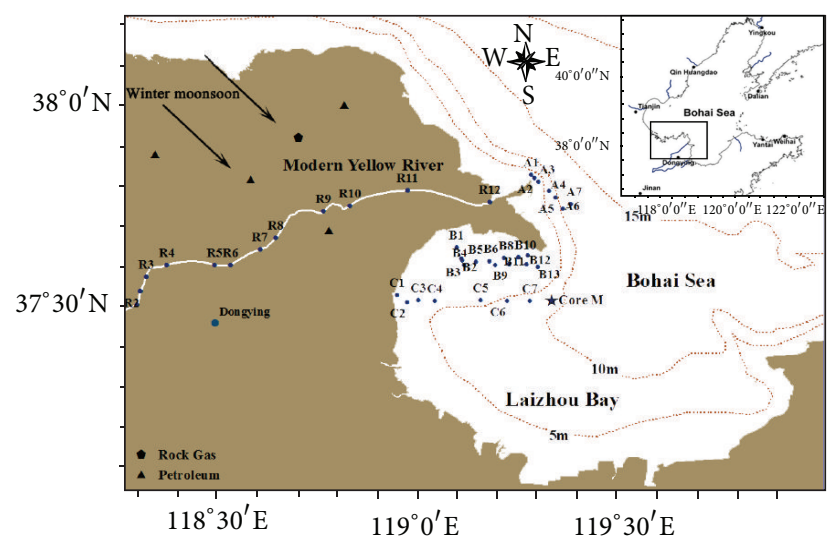

FIGURE 1: Map of study area and sampling sites in the Yellow River-dominated continental margin. The arrows show prevailing northwesterly wind in winter and spring. Star denotes the site of sediment core.

during the 20th century in the Yellow Sea, the South China Sea, and the East China Sea [16-19]. Here we measured PAHs in surface sediments and in a sediment core from the lower Yellow River and Bohai Sea. Our main objectives are (1) to evaluate sources of PAHs (e.g., pyrogenic versus petrogenic) in the surface sediments from the Yellow River, estuary, and coast and (2) to assess the relationship between PAHs and local socioeconomic conditions over the past eight decades.

\section{Material and Methods}

2.1. Study Area and Sampling. The Bohai Sea, a shallow, semiclosed sea in northeastern China, has a surface area of $77,000 \mathrm{~km}^{2}$ and an average water depth of $18 \mathrm{~m}$ [20]. Yellow River, ranking as the world second largest river in term of sediment load [14], has been flowing into the Bohai Sea since 1855 [21, 22]. In July 2011, a total of 39 surface sediment samples $(\mathrm{ca} .0-20 \mathrm{~cm}$ ) were retrieved from the lower Yellow River, estuary, and Laizhou Bay (southern Bohai Sea) by a steel grab sampler, from which the top $\sim 5 \mathrm{~cm}$ sediments were picked up by a steel spatula (Figure 1). Due to large terrestrial material inputs, the sedimentation rate is high $(>0.8 \mathrm{~cm}$ per year) in the Yellow River-dominated margin $[23,24]$. Consequently, the top $5 \mathrm{~cm}$ sediments represent $<7$ year sedimentation history. According to geographical locations, the surface samples were classified into four groups, namely, Yellow River (YR) (Sites R1-R12), modern estuary (Sites A1-A7), old estuary (Sites B1-B13), and the coast (Sites C1-C7) (Figure 1). In addition, a $65 \mathrm{~cm}$ long piston core $\left(119^{\circ} 18.999^{\prime} \mathrm{N}, 37^{\circ} 30.906^{\prime} \mathrm{E}\right)$ was retrieved from Laizhou Bay and was subsectioned on board of ship into $1 \mathrm{~cm}$ segments. All samples were transported to the laboratory within 48 hours and frozen at $-20^{\circ} \mathrm{C}$ until analysis. Twelve samples were selected from the sediment core at every $6 \mathrm{~cm}$ interval for the PAH analysis.

2.2. Sediment Dating. The detailed methods about ${ }^{137} \mathrm{Cs}$ and ${ }^{210} \mathrm{~Pb}$ dating have been reported [23]. The total 40 core samples were used for the radionuclide measurement. About $5 \mathrm{~g}$ dried sediments were used for ${ }^{137} \mathrm{Cs}$ and ${ }^{210} \mathrm{~Pb}$ measurements. Counting times of ${ }^{137} \mathrm{Cs}$ and ${ }^{210} \mathrm{~Pb}$ were typically in the range $50,000-86,000 \mathrm{~s}$, giving a measurement precision of between ca. $\pm 5 \%$ and $\pm 10 \%$ at the $95 \%$ level of confidence, respectively. The results showed a mean sedimentation rate of $0.87 \mathrm{~cm}$ per year for the upper part $(41.5$ to $0 \mathrm{~cm})$ and $0.73 \mathrm{~cm}$ per year for the lower part (65 to $41.5 \mathrm{~cm}$ ) [24].

2.3. Total Organic Carbon (TOC) Analyses. The sediments were freezing dried at $-50^{\circ} \mathrm{C}$ and grounded into fine powder. After the addition of excess $1 \mathrm{~N}$ hydrochloric acid to completely remove inorganic carbon, TOC was measured by an Elementar Vario EL element analyzer. The standard deviation based on the replicate analyses was $\pm 0.02 \%$ for TOC.

2.4. Sample Extraction and Clean-Up. Freeze-dried sediments ( $10 \mathrm{~g})$ were homogenized by a mortar and pestle. After addition of surrogate standards (2-fluorobiphenyl, $p$ terphenyl- $\left.\mathrm{d}_{14}\right)$, samples were extracted $(3 \times)$ with $20 \mathrm{~mL} n$ hexane/acetone $(1: 1, \mathrm{v} / \mathrm{v})$ in an ultrasonic bath. The extract was evaporated to $1 \mathrm{~mL}$ at $35^{\circ} \mathrm{C}$ with a rotary evaporator and then fractionated over silica gel/alumina column $(30 \mathrm{~cm}$; $10 \mathrm{~mm}$ i.d.). The column was first eluted with $25 \mathrm{~mL} n$-hexane to remove non-PAHs such as aliphatic hydrocarbons and then with $50 \mathrm{~mL}$ mixed dichloromethane and $n$-hexane $(1: 1$, $\mathrm{v} / \mathrm{v})$ for PAHs. The second fraction was concentrated with the rotary evaporator at $35^{\circ} \mathrm{C}$. After addition of $5 \mathrm{~mL} n$ hexane, the mixed solution was evaporated to nearly $1 \mathrm{~mL}$, spiked with recovery standards including five deuterated PAHs (naphthalene- $\mathrm{d}_{8}$, acenaphthene- $\mathrm{d}_{10}$, phenanthrene$\mathrm{d}_{10}$, chrysene- $\mathrm{d}_{12}$, and perylene- $\mathrm{d}_{12}$ ), and stored in a $2 \mathrm{~mL}$ vial capped with a Teflon-lined septum for further analysis.

2.5. Sample Analysis. PAHs were determined on an Agilent 7890A gas chromatography (GC) coupled to a 5975C mass selective detector (MSD). The separation was achieved on a HP-5 MS capillary column $(30 \mathrm{~m} \times 0.25 \mathrm{~mm}$ i.d. $\times 0.25 \mu \mathrm{m}$ film thickness) in a splitless injection mode. The injection temperature was $280^{\circ} \mathrm{C}$. The column temperature was programmed from $80^{\circ} \mathrm{C}$ (held for $1 \mathrm{~min}$ ) to $270^{\circ} \mathrm{C}$ at a rate of $5^{\circ} \mathrm{C} \mathrm{min}{ }^{-1}$, then increased to $300^{\circ} \mathrm{C}$ at a rate of $3^{\circ} \mathrm{C} \mathrm{min}{ }^{-1}$, and held at $300^{\circ} \mathrm{C}$ for $8 \mathrm{~min}$ to purge the chromatographic column. Helium (>99.999\%) was used as the carrier gas. The mass spectrometry was operated in the selected ion monitoring (SIM) mode with an electron impact ionization of $70 \mathrm{eV}$, an ion source of $230^{\circ} \mathrm{C}$, and an electron multiplier voltage of $1235 \mathrm{~V}$.

All samples were analyzed for 16 USEPA priority PAHs, including naphthalene (Nap), acenaphthene (Ace), acenaphthylene (Any), fluorine (Fl), phenanthrene (Phe), anthracene (An), fluoranthene (Fla), pyrene (Pyr), benz[a]anthracene (BaA), chrysene (Chr), benzo[b]fluoranthene $(\mathrm{BbF})$, benzo[k]fluoranthene $(\mathrm{BkF})$, benzo[a]pyrene (BaP), indeno[1,2,3-cd]pyrene (IcdP), dibenz[a,h]anthracene (dBA), and benzo[g,h,i]perylene (BPe). Additionally, alkyl PAHs such as 1-methyl phenanthrene (1-MP), 2-methyl phenanthrene (2-MP), 3-methyl phenanthrene (3-MP), and 9-methyl phenanthrene 
TABLE 1: Linear correlations $(R)$ of TOC against PAH concentration ( $\mathrm{ng} \mathrm{g}^{-1} \mathrm{dws}$ ) along the transect of lower Yellow River (YR), river mouth, and adjacent sea.

\begin{tabular}{lccccc}
\hline PAHs & lower YR & Modern estuary & Old estuary & Coast & Entire areas \\
\hline $2+3$ rings & 0.60 & 0.60 & 0.62 & 0.97 & 0.63 \\
4 rings & 0.57 & 0.39 & 0.82 & 0.96 & 0.53 \\
$5+6$ rings & 0.59 & 0.55 & 0.75 & 0.95 & 0.54 \\
\hline
\end{tabular}

All probability $(P)$ values are lower than 0.001 . The number of samples $(n)$ is 12 for the lower YR, 7 for the old estuary, 13 for the modern estuary, and 7 for the coast.

(9-MP) were also measured and quantified according to the respective peak areas. The four methyl phenanthrene isomers were summed and reported as total methyl phenanthrenes (MP).

2.6. Quality Assurance and Quality Control. Procedural blanks, spiked blanks, spiked matrixes, and parallel samples were performed to control data quality. As low molecular weight (LMW; $2+3$ rings) PAHs like Nap and Phe were abundant in the atmosphere, two procedural blanks were added for every ten sample pretreatments. The mean blank value was subtracted from all samples. The detection limits for individual PAH ranged from 0.2 to $2.2 \mathrm{ng} \mathrm{g}^{-1} \mathrm{dws}$ (dry weight sediment). The recoveries of PAHs in the matrix spiked samples $(n=3)$ ranged from $69.6 \%$ (Nap) to $100.5 \%(\mathrm{BkF})$, and the recoveries of the surrogates (2fluorobiphenyl, $p$-terphenyl- $\mathrm{d}_{14}$ ) accounted for $51.9 \pm 8.5 \%$ and $83.0 \pm 11.8 \%(n=51)$, respectively (Supplementary Table 1 in Supplementary Material available online at http://dx.doi.org/10.1155/2014/654183). The instrumental precision was determinedby analyzing a standard containing 100 ppb PAHs and 200 ppb deuterated PAHs, and the standard deviation (SD) was less than $5 \%$ of the measured values $(n=10)$. Among all sediments, the sample R7 was used for the parallel experiment, and its relative standard deviation (RSD; $n=3$ ) was less than $15 \%$, demonstrating that our experimental processes including extraction, clean-up, and GC-MS analysis were well controlled.

2.7. Statistical Analysis. To better assess the spatial differences in the PAHs' distribution, a principal component analysis (PCA) was performed (SPSS 17.0, Illinois USA). All 39 samples were included in our PCA. However, two PAHs, Nap and An, were excluded in the PCA because Nap is the most volatile $\mathrm{PAH}$ with low environmental stability, while the concentration of An is too low to be quantified in several samples. PAHs were processed on basis of their concentrations ( $\mathrm{ng} \mathrm{g}^{-1} \mathrm{dws}$ ).

\section{Results and Discussion}

3.1. Concentration and Source of PAHs in Surface Sediments. The concentration of 16 USEPA priority PAHs ( $\Sigma 16$ PAHs) ranged from 5.6 to $175.4 \mathrm{ng} \mathrm{g}^{-1}$ dws with a mean of $49.1 \mathrm{ng} \mathrm{g}^{-1}$ dws in our study (Figure 2). Hu et al. [7] and Hui et al. [12] reported a mean $\Sigma 16$ PAHs of $175.7 \mathrm{ng} \mathrm{g}^{-1}$ dws (97.2$300.7 \mathrm{ng} \mathrm{g}^{-1} \mathrm{dws}$ ) and $90.7 \mathrm{ng} \mathrm{g}^{-1}$ dws (10.8-252 $\left.\mathrm{ng} \mathrm{g}^{-1} \mathrm{dws}\right)$, respectively. Therefore, our study has lower $\mathrm{PAH}$ abundance compared to previous studies for the Bohai Sea [7, 10-12]. Two factors may explain this difference. First, our samples are from the southern portion of Bohai Sea (Figure 1), further away from Beijing and Tianjin, two megacities near the Bohai Sea with population of over 30 million $[10,11]$. Second, the implementation of new energy policy has replaced coal with clean energy resources such as natural gas and hydropower, which reduced the $\mathrm{PAH}$ emissions.

Sedimentary TOC can play an important role in $\mathrm{PAH}$ accumulation. This was investigated in the present study. Table 1 shows linear correlations $(r)$ of sedimentary TOC contents with different ring PAHs on the basis of 39 surface sediments. Overall, a positive correlation $(r=0.54 \sim$ 0.63; $P<0.001$ ) was observed between TOC and PAHs, confirming that sedimentary organic carbon has a somewhat influence on the PAH concentrations in the surface sediments from the Yellow River-dominated margin. The $r$ values were the highest for sediments from the coast $(>0.95)$, followed by the old estuary (0.62 0.82), the lower Yellow River $(0.57 \sim$ $0.60)$, and the modern estuary $(0.39 \sim 0.60)$. Such difference suggests that an adsorption equilibrium between PAHs and sedimentary TOC has been reached in the coastal area after the long-range transport of terrestrial materials from land to sea, whereas other factors such as mineral size may also contribute to $\mathrm{PAH}$ accumulation to some degree in the river and estuaries.

In our study, the PAHs with 2-3 rings, 4 rings, and 56 rings accounted for $60 \pm 11 \%, 29 \pm 7 \%$, and $11 \pm 5 \%$ of total PAHs, respectively (Supplementary material Table 2). The predominance of low molecular weight (LMW) over high molecular weight (HMW) PAHs may reflect either preferential inputs of LMW PAHs or an important contribution of petrogenic products or biomass and coal burning at low to moderate temperatures $[7,25]$. LMW $(2+3$ rings $)$ PAHs are more volatile and thus are preferentially delivered by atmospheric transport. In addition, LMW PAHs are more abundant in petrogenic products and low to moderate temperature combustion processes (e.g., biomass and coal burning in homes and small factories), whereas HMW (5+ 6 rings) PAHs are products of high temperature combustions involving coal and petroleum such as large power plants and factories, vehicular emissions, and gas-fired cooking operations $[26,27]$.

PAHs with a petrogenic origin are usually abundant in alkyl PAHs relative to their parent compounds, while those with a pyrogenic (combustion) origin contain little or no alkyl PAHs [28, 29]. In our study, the ratio of alkyl:parent 


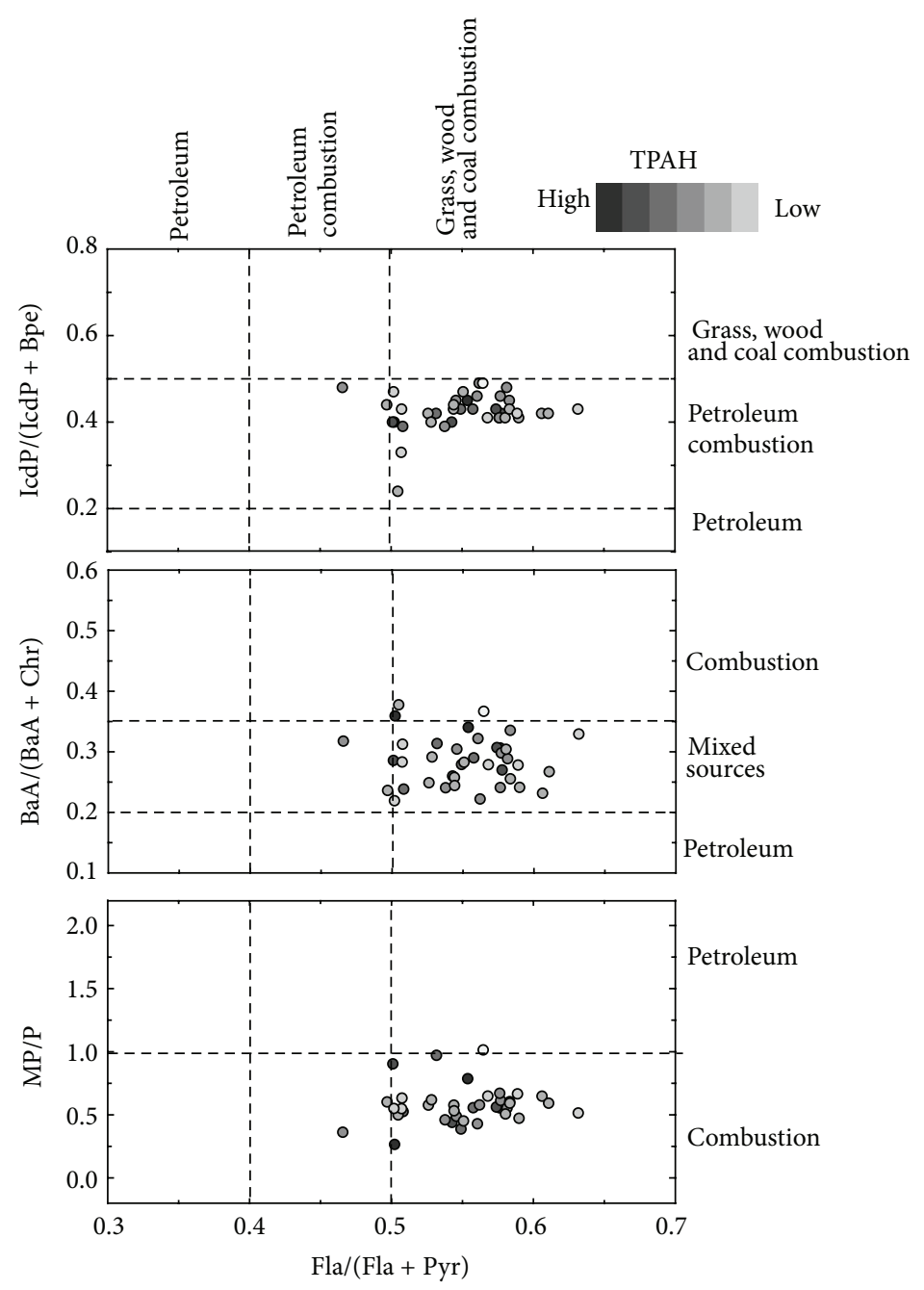

FIGURE 2: Cross plot of PAHs based on different diagnostic ratios for surface sediments from the Yellow River-dominated continental margin. (a) IcdP/(IcdP + Bpe) versus Fla/(Fla + Pyr); (b) BaA/(BaA + Chr) versus Fla/(Fla + Pyr); (c) MP/P versus Fla/(Fla + Pyr). IcdP: indeno[1,2,3cd]pyrene; Bpe: benzo[g,h,i]perylene; Fla: fluoranthene; Pyr: pyrene; BaA: benz[a] anthracene; Chr: chrysene; MP: methyl phenanthrenes; P: phenanthrenes. The dash lines represent the thresholds for different sources [1].

PAHs has a mean value of $0.58 \pm 0.17$ in the lower Yellow River, $0.60 \pm 0.14$ in the modern estuary, $0.53 \pm 0.11$ in the old estuary, and $0.63 \pm 0.18$ at the coast. The predominance of parent over alkyl PAHs suggests that PAHs in surface sediments of the southern Bohai Sea are mainly produced by pyrogenic processes. One exception is site C7 from the coastal area, which contains more abundant alkyl PAHs than parent PAHs. This suggests an important contribution of petrogenic products probably from oil spills since the Bohai Sea is a busy shipping channel and an important offshore oil base in China $[7,30]$.

Yunker et al. (2002) proposed that the Fla/(Fla + Pyr) ratio of $0.4-0.5$ and $>0.5$ is indicative of liquid fossil fuel combustion and coal/grass/wood combustion, respectively, whereas the $\mathrm{BaA} /(\mathrm{BaA}+\mathrm{Chr})$ ratio of $0.2,0.20-0.35$, and $>0.35$ suggests $\mathrm{PAHs}$ primarily from petroleum, mixed petroleum/combustion, and coal/wood combustion, respectively. In addition, the $\mathrm{IcdP} /(\mathrm{IcdP}+\mathrm{Bpe})$ ratio of $<0.2$,
$0.2-0.5$, and $>0.5$ is characteristic of petroleum, petroleum combustion, and coal/wood combustion, respectively [1]. In surface sediments from the Yellow River-dominated margin, $\mathrm{Fla} /(\mathrm{Fla}+\mathrm{Pyr}), \mathrm{BaA} /(\mathrm{BaA}+\mathrm{Chr})$, and $\mathrm{IcdP} /(\mathrm{IcdP}+\mathrm{Bpe})$ vary from 0.47 to $0.63,0.22$ to 0.38 , and 0.24 to 0.49 , respectively (Figure 2), suggesting that PAHs are mainly produced by the combustions of coal and biomass, while the contribution of liquid fossil fuel combustion is minor [1]. This source apportionment is consistent with the current energy structure of China. It has been reported that over 1.2 billion tons of coal are consumed annually in China, representing $70 \%$ of domestic energy consumption [31]. In rural areas of China, wood, grass, and crop-stalk have been widely used for cooking and heating, representing an additional contributor for PAHs [32]. Compared to oil and natural gas, the combustion of coal and biomass releases more PAHs per unit of power generated $[33,34]$. Therefore, it is not surprising that the combustion of coal and biomass is 

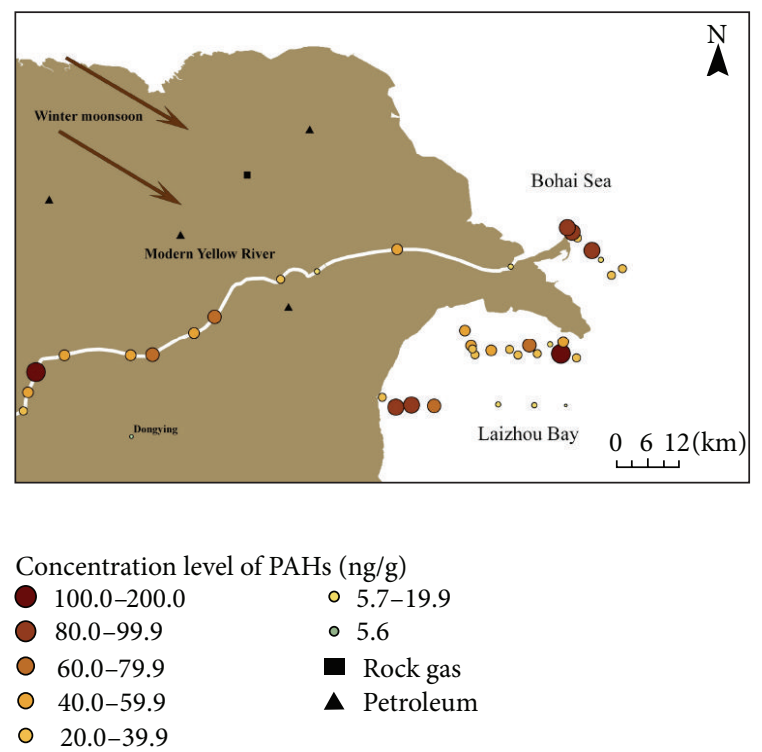

FIgURe 3: Spatial distributions of PAHs in surface sediments along the transect of lower Yellow River, river mouth, and adjacent sea.

the most important source for PAHs in the Yellow Riverdominated margin.

3.2. Fluvial versus Atmospheric Inputs of PAHs. As semivolatile and relatively refractory compounds, PAHs can be transported from land to sea via atmosphere [35]. In winter and spring, the northwesterly winds predominate in the East Asian continent, carrying dust (including PAHs) to the north Pacific $[25,36]$. The Bohai Sea is downwind to the Chinese mainland and in the pathway of the outflow East Asian dust in winter and spring (Figure 1). As a result, large amounts of air particles and associated PAHs were deposited in the Bohai Sea [37]. Hafner and Hites [38] observed that the gasphase reactivity increased with increasing molecular weight of PAHs. Thus, if atmospheric deposition was a sole input pathway for PAHs, relative abundance of HMW PAHs would present a decreasing trend towards sea. Such trend was not observed in our study. From lower Yellow River to the coast, the relative abundance of PAHs with 2-3 rings, 4 rings, and $5-6$ rings varied in a narrow range of $59 \%$ to $61 \%, 28 \%$ to $30 \%$, and $10 \%$ to $12 \%$, respectively (Supplementary material Table 2). The mean $\Sigma 16$ PAHs was $57.6 \pm 46.6 \mathrm{ng} \mathrm{g}^{-1} \mathrm{dws}$ in the lower Yellow River, $51.7 \pm 38.0 \mathrm{ng} \mathrm{g}^{-1} \mathrm{dws}$ in the modern river estuary, $44.6 \pm 26.4 \mathrm{ng} \mathrm{g}^{-1}$ dws in the old river estuary, and $45.9 \pm 38.9 \mathrm{ngg}^{-1} \mathrm{dws}$ at the coast (Figure 3 ). A statistical analysis shows no significant difference for the PAH concentrations among different sites $(P>0.05)$. These distribution patterns of PAHs suggested the existence of other input pathways besides atmospheric transport.

PAHs are easily adsorbed on surface or occluded inside of suspended particles because of their hydrophobic properties. The particle-associated PAHs can be transported to the sea via runoff [22]. Lin et al. [25] reported riverine transport as a major input pathway of petroleum-derived PAHs in estuarine

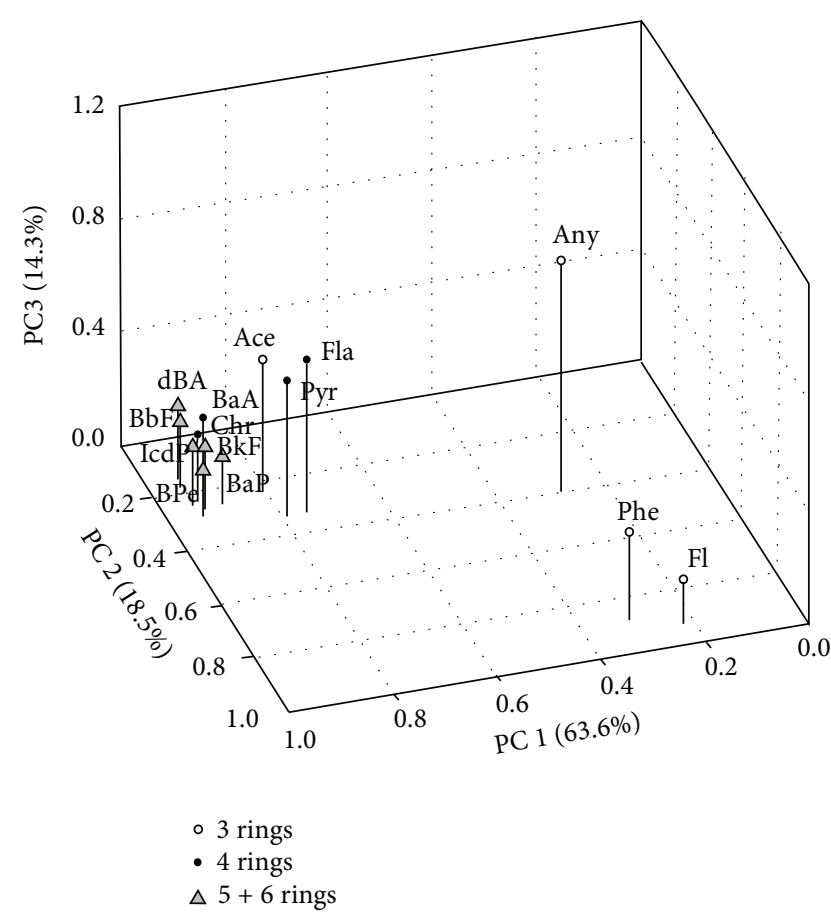

FIGURE 4: 3D loading plot of principal component analysis (PCA) for PAHs in surface sediments from the Yellow River-dominated margin. PC: principal component.

and coastal areas. In contrast to atmospheric transport, fluvial transport is an enrichment process for HMW PAHs because LMW PAHs are more readily desorbed from sediments in aquatic environments and therefore are more prone to degradation $[39,40]$. Given these facts, a homogenous distribution of $\Sigma 16$ PAHs in surface sediments suggests complex transport mechanisms in the Yellow River-dominated margin.

3.3. Principal Components Analysis of PAHs. The PCA result shows that the first three principal components (PC) account for $96.5 \%$ of total variances (Figure 4). The PC 1 (63.6\%) is characterized by high positive loadings of HMW PAHs (>0.75) including BaA, Chr, BkF, BbF, BaP, IcdP, dBA, and BPe. These 4-6 ring PAHs are primarily derived from the high temperature combustion of fossil fuel and biomass [37]. The PC 2 (18.5\%) is positively correlated with LMW PAHs including $\mathrm{Fl}$ and Phe (loadings of $>0.8$ ). These 3 ring PAHs are of a petrogenic origin or produced by the low temperature combustion of coal and biomass [37]. The PC 3 (18.5\%) has high positive loadings ( $>0.48$ ) of Any, Ace, Fla, and Pyr. These 3-4 ring PAHs have mixed pyrogenic/petrogenic sources. Our PCA result demonstrates that PAHs in the surface sediments have a predominant pyrogenic source from the combustion of coal, biomass, and petroleum [27, 41-43], while the inputs from the petrogenic source such as oil spill is minor $[44,45]$. The PCA result agrees well with the source apportionment from molecular diagnostic indicators (see Section 3.1).

3.4. Temporal Distribution of PAHs. Figure 5 shows historical variations of $\Sigma 16$ PAHs (37 to $211 \mathrm{ng} \mathrm{g}^{-1} \mathrm{dws}$ ) in the southern 


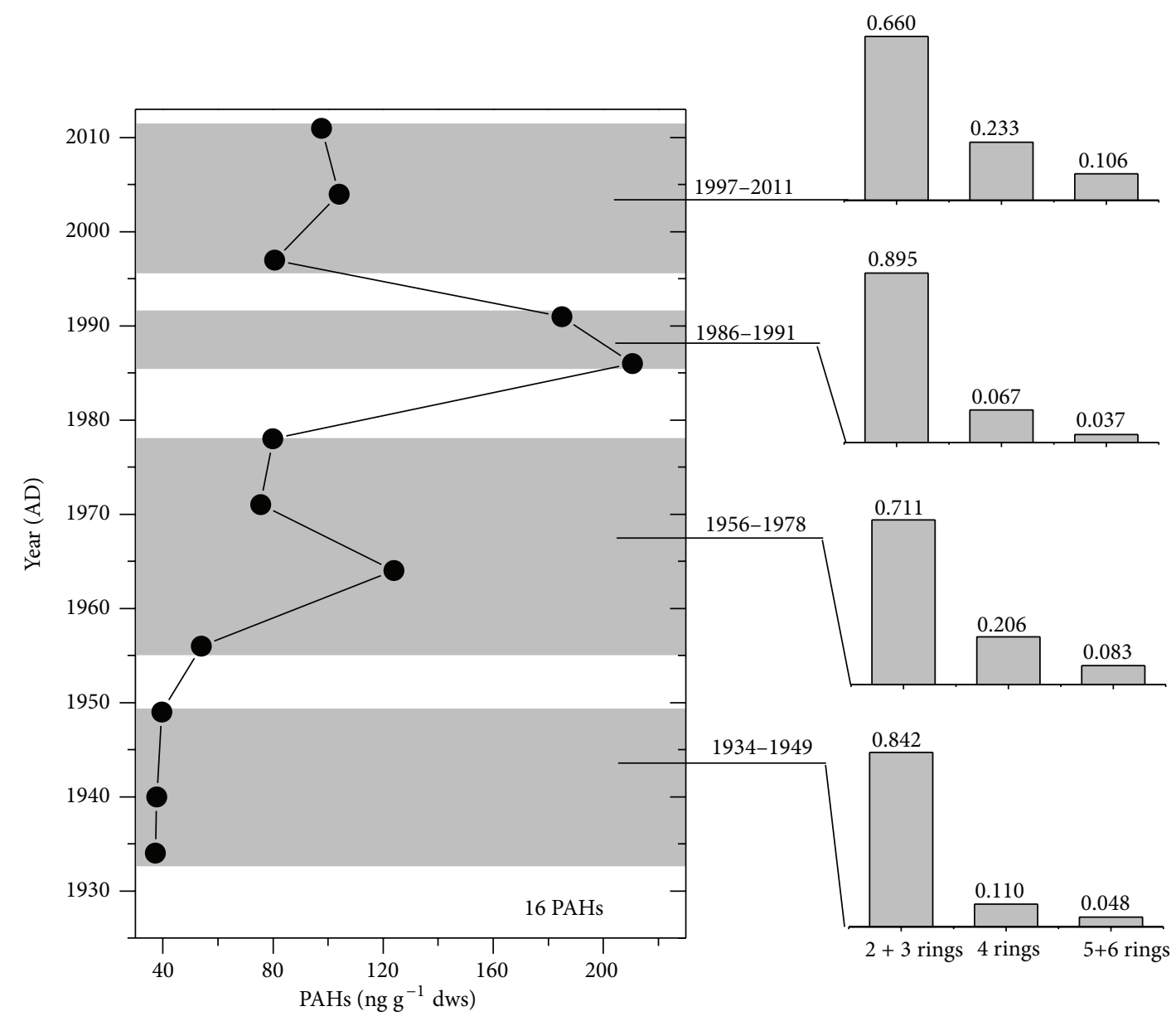

FIGURE 5: Historical distributions in abundance of total 16 PAHs (ng g ${ }^{-1}$ dws) and percentage of $2+3$, 4, and $5+6$ ring PAHs in sediment core from Southern Bohai Sea.

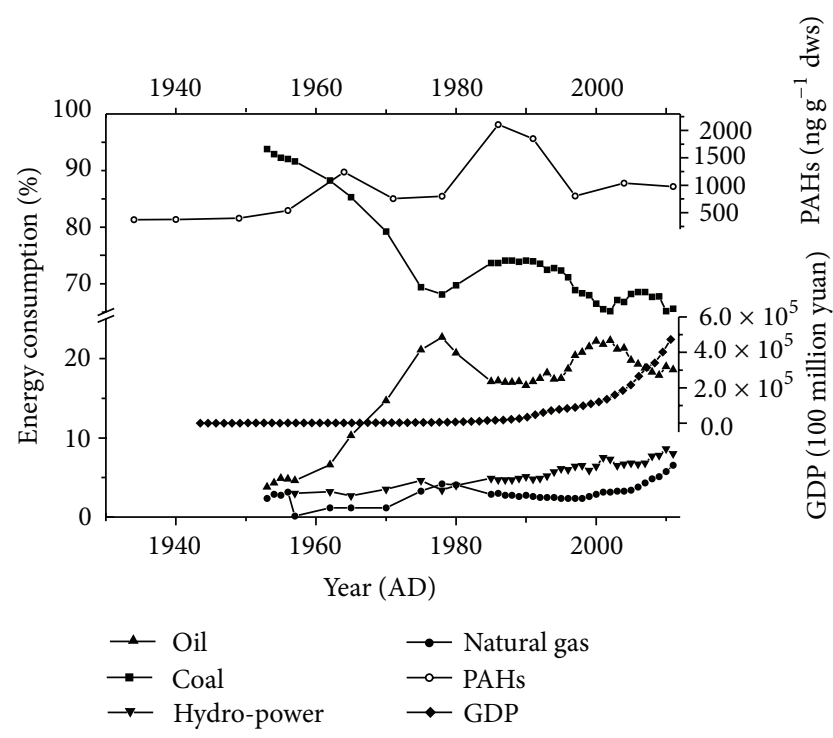

FIgURE 6: Relationship between sedimentary PAH concentrations (ng $\mathrm{g}^{-1} \mathrm{dws}$ ) in southern Bohai Sea and energy consumption of China.
क Bohai Sea during the period of ca. 1930-2011. Prior to 1950, the $\Sigma 16$ PAHs remained lower than $40 \mathrm{ngg}^{-1} \mathrm{dws}$, synchronous with the WWII (1937-1945) and the Chinese Civil War (1946-1949). During this period, many factories moved to inner China from the coastal areas. Our result agrees well with the report by Guo et al. [37] who observed low abundance of $\Sigma 16$ PAHs from 1937 to 1949 in the East China Sea. Starting in 1950, the $\Sigma 16$ PAHs increased significantly in the Bohai Sea and reached a maximum in 1964 (124 $\mathrm{ng} \mathrm{g}^{-1}$ dws). From 1964 to 1978, the $\Sigma 16$ PAHs declined to $78 \mathrm{ng} \mathrm{g}^{-1}$ dws, which is synchronous with the Cultural Revolution in China (1966-1976). During this 10-year period, China was in a long-term recession and many factories were ceased because of political conflicts. A similar decline for PAHs was observed in the South China Sea [16] and the East China Sea [37]. After 1978, the $\Sigma 16$ PAHs substantially increased to $210 \mathrm{ng} \mathrm{g}^{-1}$ dws in 1986 and remained at this high level until early 1990s. This stage with high PAH abundance is consistent with the fast economic development of China after the termination of the Cultural Revolution in 1976 and the initiation of the "Reform and Open Policy" in 1978. However, 


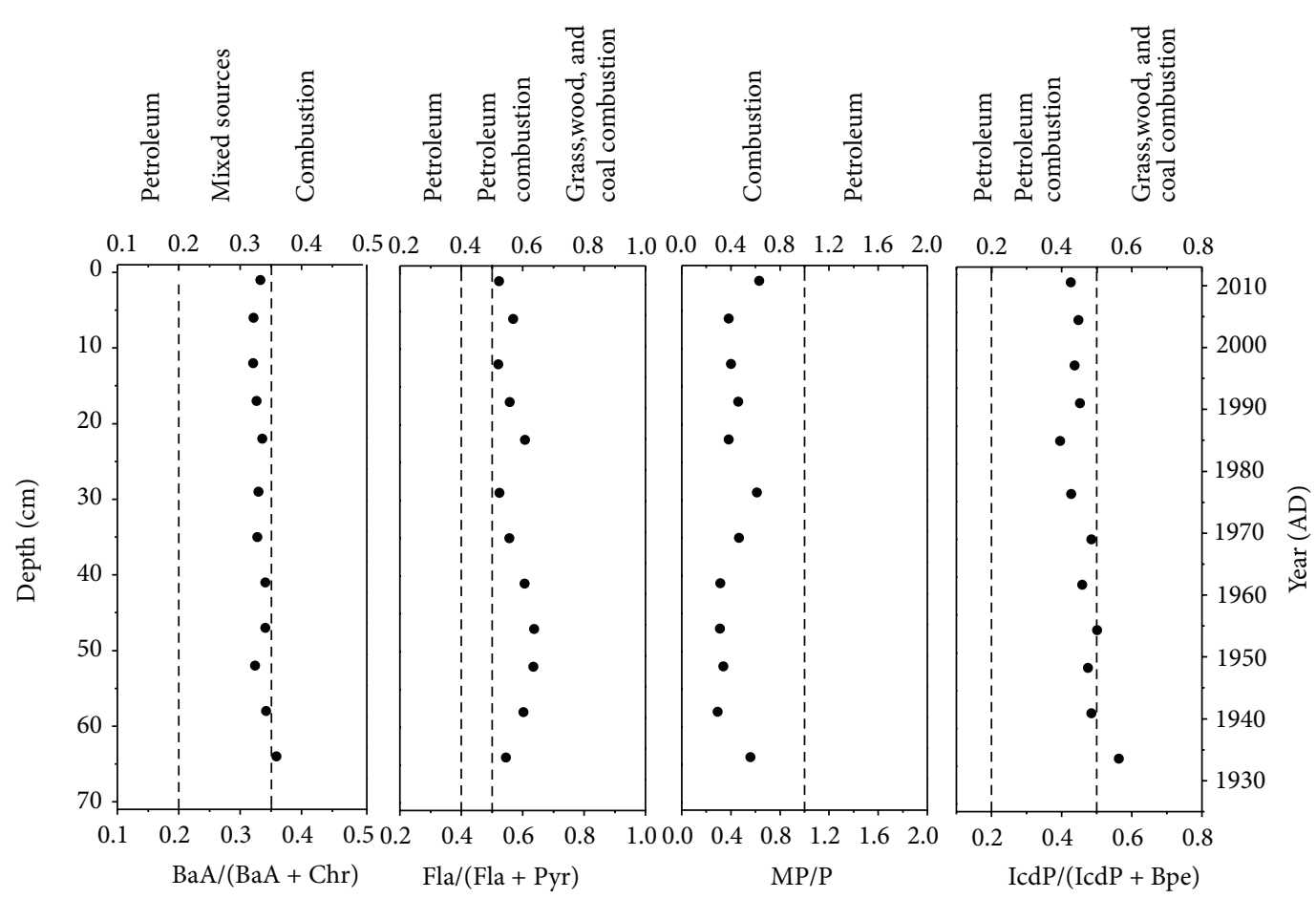

Figure 7: Historical profiles of diagnostic ratios of PAHs in sediment core from southern Bohai Sea, China. IcdP: indeno[1,2,3-cd]pyrene; Bpe: benzo[g,h,i]perylene; Fla: fluoranthene; Pyr: pyrene; BaA: benz[a]anthracene; Chr: chrysene; MP: methyl phenanthrenes; P: phenanthrenes. The dash lines represent the thresholds for different sources [1].

the $\Sigma 16$ PAHs decreased to $80 \mathrm{ng} \mathrm{g}^{-1}$ dws after 1990 despite a continuous economic growth in China (Figure 6; NBSC, 2012). This decoupling between the economic condition and the PAH abundance is likely induced by the switch of the energy structure in China. Since 1990, increased usage of natural gas and other clean energy resources such as hydropower has caused a decrease in the proportion of coal in the energy consumption (Figure 6) [32]. It is well known that coal releases more PAHs than natural gas and oil per unit of power generated $[33,34]$. Similar phenomena have been verified in Europe and the United States as a result of energy structure changes [46, 47].

3.5. Historical Variability of PAH Sources. From 1930 to 2011, the relative abundance of $2+3$ ring PAHs generally decreased (84.2\% from 1934 to 1949 versus 66\% from 1997 to 2011), whereas the relative abundance of $5+6$ ring PAHs increased from $4.8 \%$ to $10.6 \%$ (Figure 5). This shift in the PAH composition suggests more contributions from high temperature combustion of coal and petroleum such as large power plants and factories, vehicular emissions, and gas-fired cooking operations [37]. A series of diagnostic molecular indicators such as $\mathrm{BaA} /(\mathrm{BaA}+\mathrm{Chr}), \mathrm{MP} / \mathrm{P}$, and $\mathrm{IcdP} /(\mathrm{IcdP}+\mathrm{Bpe})$ indicates that PAHs are primarily from the combustion of coal, biomass, and petroleum over the past eight decades (Figure 7). A slight decrease in the Fla/(Fla + Pyr) and IcdP/(IcdP + Bpe) after the 1970s confirms more PAH inputs from the petroleum combustion [1], consistent with an increase in usage of oil and natural gas in the Chinese energy consumption during this period (Figure 7).

\section{Conclusions}

We have examined the spatial and temporal distributions of PAHs in surface sediments and a sediment core from the lower Yellow River, estuary, and Laizhou Bay. Based on data about molecular diagnostic ratios, relative number of aromatic rings, and PCA, four conclusions have been drawn.

(1) Compared to the previous studies, the concentration of 16 USEPA priority PAHs in our study is lower, partially attributed to recent implementation of new energy policy in China. (2) The homogenous distribution of PAHs and the positive relationship between TOC and PAHs' abundance suggest a mixed input by atmospheric and riverine transport. (3) The historical PAHs' pattern in the Laizhou Bay presents a good correlation with the Chinese socioeconomic conditions during the period of 1930 to 2011, confirming that PAHs are a sensitive tracer for anthropogenic activity. (4) The PAHs in the southern Bohai Sea are primarily derived from the combustion of coal and biomass. The contribution of petroleum combustion is minor, but it increased after 1970s, consistent with the change in the Chinese energy structure.

\section{Conflict of Interests}

The authors declare that there is no conflict of interests regarding the publication of this paper. 


\section{Acknowledgments}

This study was financially supported by NSFC (41006042, 41176164), the Ministry of Education of China (SRFDP), and special fund of State Key Joint Laboratory of Environment Simulation and Pollution Control (PKU).

\section{References}

[1] M. B. Yunker, R. W. Macdonald, R. Vingarzan, R. H. Mitchell, D. Goyette, and S. Sylvestre, "PAHs in the Fraser River basin: a critical appraisal of PAH ratios as indicators of PAH source and composition," Organic Geochemistry, vol. 33, no. 4, pp. 489-515, 2002.

[2] M. B. Yunker, A. Perreault, and C. J. Lowe, "Source apportionment of elevated PAH concentrations in sediments near deep marine outfalls in Esquimalt and Victoria, BC, Canada: is coal from an 1891 shipwreck the source?" Organic Geochemistry, vol. 46, pp. 12-37, 2012.

[3] F. Wania and D. Mackay, "Tracking the distribution of persistent organic pollutants," Environmental Science \& Technology, vol. 30, no. 9, pp. 390A-396A, 1996.

[4] J. Meador, J. E. Stein, W. L. Reichert, and U. Varanasi, "Bioaccumulation of polycyclic aromatic hydrocarbons by marine organisms," in Reviews of Environmental Contamination and Toxicology, pp. 79-165, Springer, New York, NY, USA, 1995.

[5] P. Boffetta, N. Jourenkova, and P. Gustavsson, "Cancer risk from occupational and environmental exposure to polycyclic aromatic hydrocarbons," Cancer Causes and Control, vol. 8, no. 3, pp. 444-472, 1997.

[6] National Bureau of Statistics of China, Statistics Data on 60 Years of New China, China Statistics Press, 2012, (Chinese).

[7] N. Hu, P. Huang, J. Liu, X. Shi, D. Ma, and Y. Liu, "Source apportionment of polycyclic aromatic hydrocarbons in surface sediments of the Bohai Sea, China," Environmental Science and Pollution Research, vol. 20, no. 2, pp. 1031-1040, 2013.

[8] SOA, "State Oceanic Administration of China, Communique of marine quality in China seas in 2006," 2006, http://www.mlr .gov.cn/zwgk/tjxx/201004/t20100401_143687.htm.

[9] C. Wang, W. Wang, S. He, J. Du, and Z. Sun, "Sources and distribution of aliphatic and polycyclic aromatic hydrocarbons in Yellow River Delta Nature Reserve, China," Applied Geochemistry, vol. 26, no. 8, pp. 1330-1336, 2011.

[10] N. Hu, X. Shi, J. Liu, P. Huang, Y. Liu, and Y. Liu, "Concentrations and possible sources of PAHs in sediments from Bohai Bay and adjacent shelf," Environmental Earth Sciences, vol. 60, no. 8, pp. 1771-1782, 2010.

[11] W. Jiao, T. Wang, J. S. Khim et al., "PAHs in surface sediments from coastal and estuarine areas of the northern Bohai and Yellow Seas, China," Environmental Geochemistry and Health, vol. 34, no. 4, pp. 445-456, 2012.

[12] Y. Hui, M. Zheng, Z. Liu, and L. Gao, "Distribution of polycyclic aromatic hydrocarbons in sediments from Yellow River Estuary and Yangtze River Estuary, China," Journal of Environmental Sciences, vol. 21, no. 12, pp. 1625-1631, 2009.

[13] B. Men, M. He, L. Tan, C. Lin, and X. Quan, "Distributions of polycyclic aromatic hydrocarbons in the Daliao River Estuary of Liaodong Bay, Bohai Sea (China)," Marine Pollution Bulletin, vol. 58, no. 6, pp. 818-826, 2009.

[14] Y. Saito, Z. Yang, and K. Hori, “The Huanghe (Yellow River) and Changjiang (Yangtze River) deltas: a review on their characteristics, evolution and sediment discharge during the Holocene," Geomorphology, vol. 41, no. 2-3, pp. 219-231, 2001.

[15] J. Xu, Y. Yu, P. Wang, W. Guo, S. Dai, and H. Sun, "Polycyclic aromatic hydrocarbons in the surface sediments from Yellow River, China," Chemosphere, vol. 67, no. 7, pp. 1408-1414, 2007.

[16] L. Y. Liu, J. Wang, G. Wei, Y. Guan, C. S. Wong, and E. Y. Zeng, "Sediment records of Polycyclic Aromatic Hydrocarbons (PAHs) in the continental shelf of China: implications for evolving anthropogenic impacts," Environmental Science and Technology, vol. 46, no. 12, pp. 6497-6504, 2012.

[17] M. Liu, P. J. Baugh, S. M. Hutchinson, L. Yu, and S. Xu, "Historical record and sources of polycyclic aromatic hydrocarbons in core sediments from the Yangtze Estuary, China," Environmental Pollution, vol. 110, no. 2, pp. 357-365, 2000.

[18] G. Q. Liu, G. Zhang, X. D. Li, J. Li, X. Z. Peng, and S. H. Qi, "Sedimentary record of polycyclic aromatic hydrocarbons in a sediment core from the Pearl River Estuary, South China," Marine Pollution Bulletin, vol. 51, no. 8-12, pp. 912-921, 2005.

[19] Y. Wu, J. Zhang, T. Mi, and B. Li, "Occurrence of $n$-alkanes and polycyclic aromatic hydrocarbons in the core sediments of the Yellow Sea," Marine Chemistry, vol. 76, no. 1-2, pp. 1-15, 2001.

[20] D. Sun, W. Tan, Y. Pei et al., "Late quaternary environmental change of Yellow River Basin: an organic geochemical record in Bohai Sea (North China)," Organic Geochemistry, vol. 42, no. 6, pp. 575-585, 2011.

[21] J. D. Milliman and R. H. Meade, "World-wide delivery of sediment to the oceans," The Journal of Geology, vol. 91, no. 1, pp. 1-21, 1983.

[22] S. Qiao, X. Shi, A. Zhu et al., "Distribution and transport of suspended sediments off the Yellow River (Huanghe) mouth and the nearby Bohai Sea," Estuarine, Coastal and Shelf Science, vol. 86, no. 3, pp. 337-344, 2010.

[23] K. Bao, W. Xia, X. Lu, and G. Wang, "Recent atmospheric lead deposition recorded in an ombrotrophic peat bog of Great Hinggan Mountains, Northeast China, from $210 \mathrm{~Pb}$ and $137 \mathrm{Cs}$ dating," Journal of Environmental Radioactivity, vol. 101, no. 9, pp. 773-779, 2010.

[24] W. Wu, L. Zhao, Y. Pei, W. Ding, H. Yang, and Y. Xu, "Variability of tetraether lipids in Yellow River-dominated continental margin during the past eight decades: implications for organic matter sources and river channel shifts," Organic Geochemistry, vol. 60, pp. 33-39, 2013.

[25] T. Lin, L. Hu, Z. Guo et al., "Sources of polycyclic aromatic hydrocarbons to sediments of the Bohai and Yellow Seas in East Asia," Journal of Geophysical Research: Atmospheres, vol. 116, no. D23, p. D23305, 2011.

[26] B. Mai, S. Qi, E. Y. Zeng et al., "Distribution of polycyclic aromatic hydrocarbons in the coastal region off Macao, China: assessment of input sources and transport pathways using compositional analysis," Environmental Science and Technology, vol. 37, no. 21, pp. 4855-4863, 2003.

[27] R. M. Harrison, D. I. T. Smith, and L. Luhana, "Source apportionment of atmospheric polycyclic aromatic hydrocarbons collected from an urban location in Birmingham, UK," Environmental Science and Technology, vol. 30, no. 3, pp. 825832, 1996.

[28] M. B. Yunker, L. R. Snowdon, R. W. Macdonald et al., "Polycyclic aromatic hydrocarbon composition and potential sources for sediment samples from the beaufort and barents seas," Environmental Science \& Technology, vol. 30, no. 4, pp. 1310-1320, 1996.

[29] E. Y. Zeng and C. L. Vista, "Organic pollutants in the coastal environment off San Diego, California. 1. Source identification 
and assessment by compositional indices of polycyclic aromatic hydrocarbons," Environmental Toxicology \& Chemistry, vol. 16, no. 2, pp. 179-188, 1997.

[30] P. Zhang, J. Song, and H. Yuan, "Persistent organic pollutant residues in the sediments and mollusks from the Bohai Sea coastal areas, North China: an overview," Environment International, vol. 35, no. 3, pp. 632-646, 2009.

[31] W. Deng, X. G. Li, S. Y. Li, Y. Y. Ma, and D. H. Zhang, "Source apportionment of polycyclic aromatic hydrocarbons in surface sediment of mud areas in the East China Sea using diagnostic ratios and factor analysis," Marine Pollution Bulletin, vol. 70, no. 1-2, pp. 266-273, 2013.

[32] S. Xu, W. Liu, and S. Tao, "Emission of polycyclic aromatic hydrocarbons in China," Environmental Science and Technology, vol. 40, no. 3, pp. 702-708, 2006.

[33] W. F. Rogge, L. M. Hildemann, M. A. Mazurek, G. R. Cass, and B. R. T. Simoneit, "Sources of fine organic aerosol. 2. Noncatalyst and catalyst-equipped automobiles and heavy-duty diesel trucks," Environmental Science and Technology, vol. 27, no. 4, pp. 636-651, 1993.

[34] N. R. Khalili, P. A. Scheff, and T. M. Holsen, "PAH source fingerprints for coke ovens, diesel and gasoline engines, highway tunnels, and wood combustion emissions," Atmospheric Environment, vol. 29, no. 4, pp. 533-542, 1995.

[35] M. B. Fernandes, M.-A. Sicre, A. Boireau, and J. Tronczynski, "Polyaromatic hydrocarbon (PAH) distributions in the Seine River and its estuary," Marine Pollution Bulletin, vol. 34, no. 11, pp. 857-867, 1997.

[36] B. R. T. Simoneit, G. Sheng, X. Chen, J. Fu, J. Zhang, and Y. $\mathrm{Xu}$, "Molecular marker study of extractable organic matter in aerosols from urban areas of China," Atmospheric Environment A General Topics, vol. 25, no. 10, pp. 2111-2129, 1991.

[37] Z. Guo, T. Lin, G. Zhang, Z. Yang, and M. Fang, "Highresolution depositional records of polycyclic aromatic hydrocarbons in the central continental shelf mud of the East China Sea," Environmental Science and Technology, vol. 40, no. 17, pp. 5304-5311, 2006.

[38] W. D. Hafner and R. A. Hites, "Potential sources of pesticides, PCBs, and PAHs to the atmosphere of the Great Lakes," Environmental Science and Technology, vol. 37, no. 17, pp. 37643773, 2003.

[39] M. Pichler, G. Guggenberger, R. Hartmann, and W. Zech, "Polycyclic aromatic hydrocarbons (PAH) in different forest humus types," Environmental Science and Pollution Research, vol. 3, no. 1, pp. 24-31, 1996.

[40] J. V. Macías-Zamora, E. Mendoza-Vega, and J. A. VillaescusaCelaya, "PAHs composition of surface marine sediments: A comparison to potential local sources in Todos Santos Bay, B.C., Mexico," Chemosphere, vol. 46, no. 3, pp. 459-468, 2002.

[41] R. K. Larsen III and J. E. Baker, "Source apportionment of polycyclic aromatic hydrocarbons in the urban atmosphere: a comparison of three methods," Environmental Science and Technology, vol. 37, no. 9, pp. 1873-1881, 2003.

[42] A. Motelay-Massei, D. Ollivon, B. Garban, K. TiphagneLarcher, I. Zimmerlin, and M. Chevreuil, "PAHs in the bulk atmospheric deposition of the Seine river basin: source identification and apportionment by ratios, multivariate statistical techniques and scanning electron microscopy," Chemosphere, vol. 67, no. 2, pp. 312-321, 2007.

[43] Y. Liu, L. Chen, Q. Huang, W. Li, Y. Tang, and J. Zhao, "Source apportionment of polycyclic aromatic hydrocarbons (PAHs) in surface sediments of the Huangpu River, Shanghai, China," Science of the Total Environment, vol. 407, no. 8, pp. 2931-2938, 2009.

[44] R. A. Dobbins, R. A. Fletcher, B. A. Benner Jr., and S. Hoeft, "Polycyclic aromatic hydrocarbons in flames, in diesel fuels, and in diesel emissions," Combustion and Flame, vol. 144, no. 4, pp. 773-781, 2006.

[45] Y. Bixiong, Z. Zhihuan, and M. Ting, "Pollution sources identification of polycyclic aromatic hydrocarbons of soils in Tianjin area, China," Chemosphere, vol. 64, no. 4, pp. 525-534, 2006.

[46] M. F. Simcik, S. J. Eisenreich, K. A. Golden et al., "Atmospheric loading of polycyclic aromatic hydrocarbons to Lake Michigan as recorded in the sediments," Environmental Science \& Technology, vol. 30, no. 10, pp. 3039-3046, 1996.

[47] P. Fernández, R. M. Vilanova, C. Martínez, P. Appleby, and J. O. Grimalt, "The historical record of atmospheric pyrolytic pollution over Europe registered in the sedimentary PAH from remote mountain lakes," Environmental Science and Technology, vol. 34, no. 10, pp. 1906-1913, 2000. 

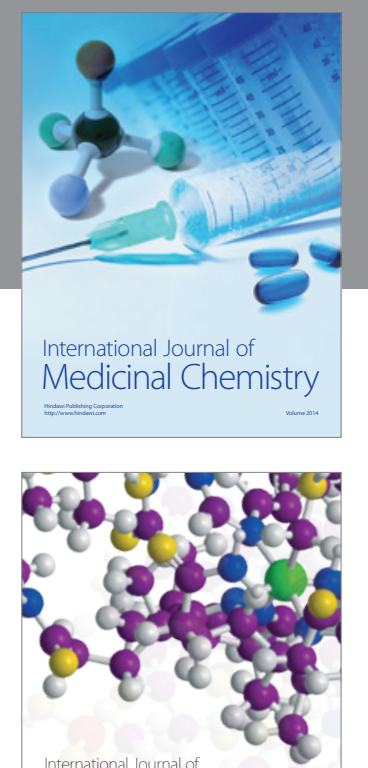

\section{Carbohydrate} Chemistry

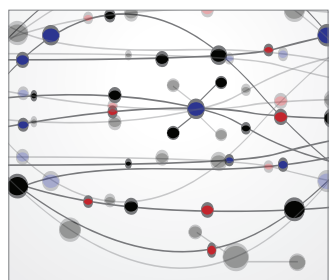

The Scientific World Journal
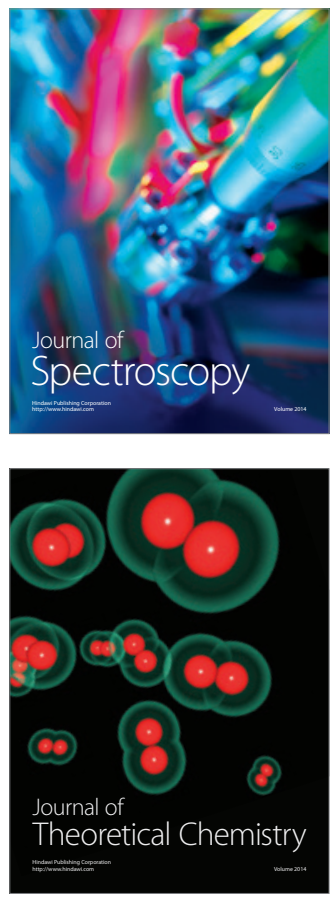
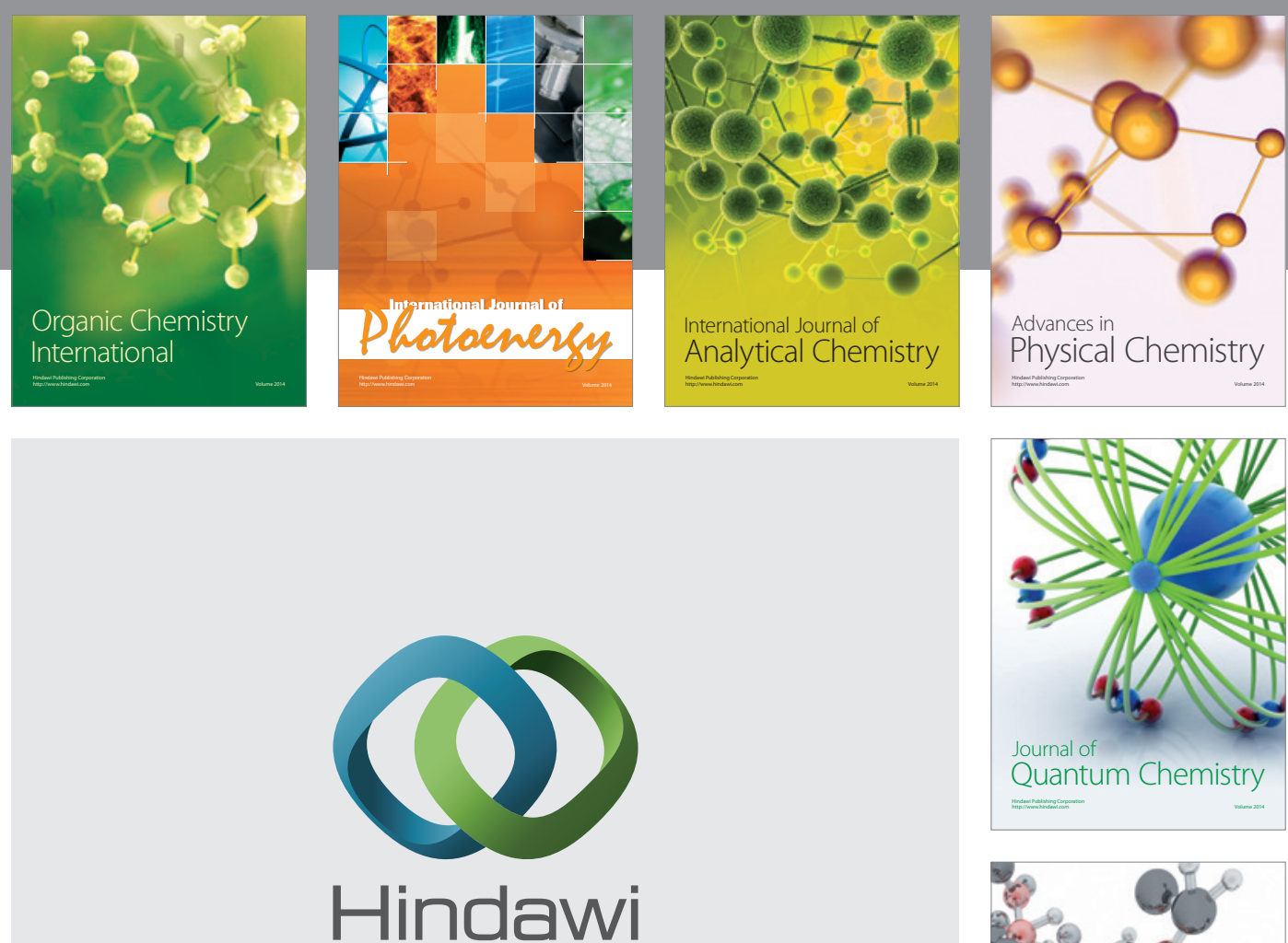

Submit your manuscripts at

http://www.hindawi.com

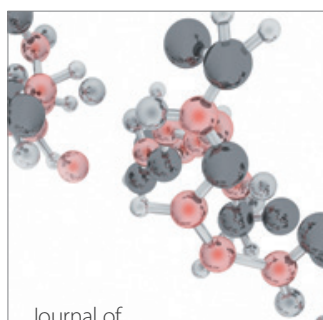

Analytical Methods

in Chemistry

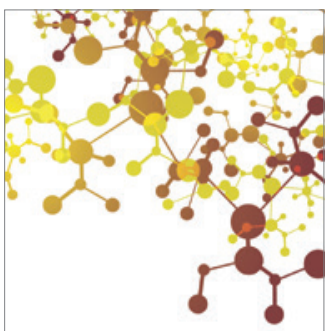

Journal of

Applied Chemistry

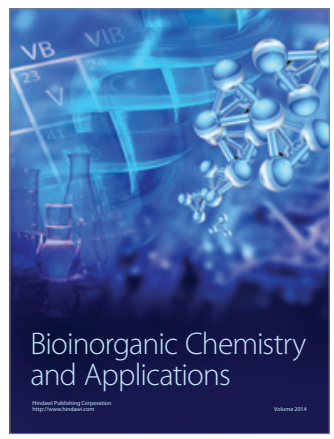

Inorganic Chemistry
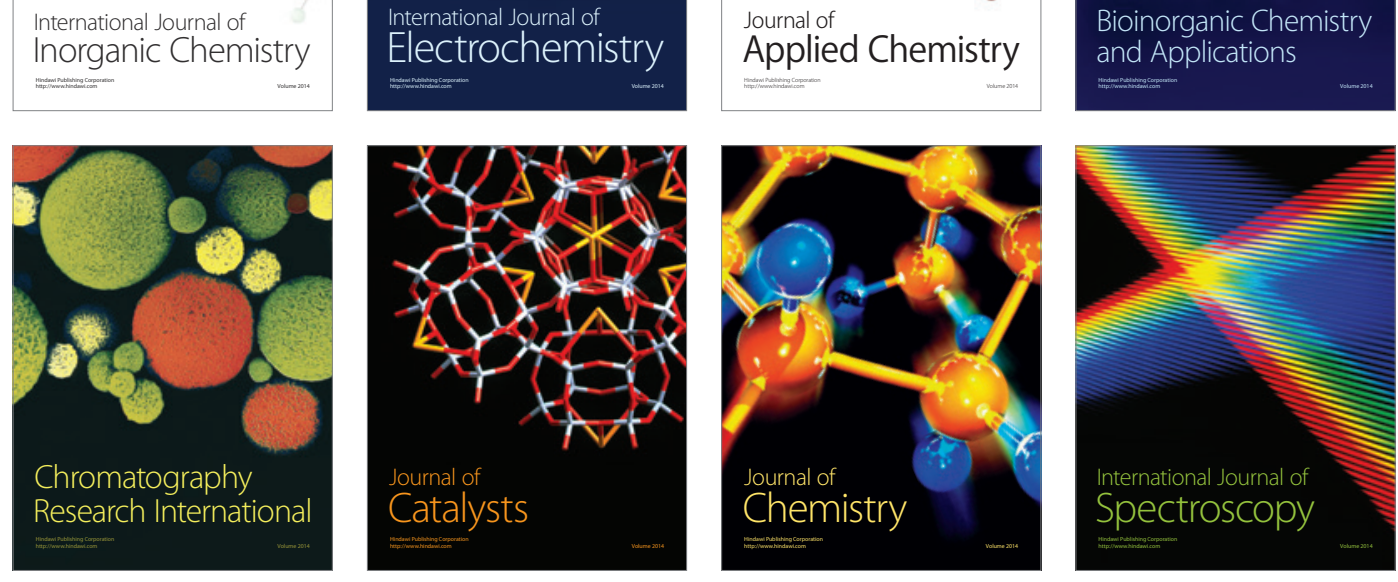